\title{
Profitability of Grazing Versus Mechanical Forage Harvesting on New York Dairy Farms
}

\author{
B. A. Gloy, L. W. Tauer, and W. Knoblauch \\ Department of Applied Economics and Management, \\ Cornell University, Ithaca, NY 14853
}

\begin{abstract}
The profitability of rotational grazing versus mechanical harvesting of forages was estimated using data from 237 nongrazing and 57 grazing farms participating in the New York farm business summary program in the year 2000. The objective was to perform an empirical comparison of the profitability of grazing versus mechanical forage harvesting systems. A regression analysis technique that controls for treatment selection bias is used to determine the impact of grazing on the rate of return on assets. This is accomplished by joint maximum likelihood estimation of a probit adoption function and a profit function. The results indicate that treatment selection does not have an important impact on the estimate of the profitability of grazing. There were wide ranges and overlap of profitability among herds using the two systems. However, other things equal, farmers utilizing grazing systems were at least if not more profitable than farmers not using grazing systems. After controlling for the factors influencing the decision to graze, we found that herd size, rate of milk production per cow, and prices received for milk have a strong positive impact on profitability. Farmers who perceive potential lifestyle benefits that might be obtained by implementing a grazing system likely do not have to pay an income penalty for adopting a grazing system.
\end{abstract}

(Key words: grazing, profitability, farm management)

Abbreviation key: OLS = ordinary least squares, ROA $=$ rate of return on assets.

\section{INTRODUCTION}

Dairy farm managers make a variety of decisions that influence the profitability of their farms. These decisions include operational decisions made on a daily basis as well as strategic decisions that impact the longterm operation of the business. Strategic decisions are

Received February 14, 2002

Accepted April 1, 2002.

Corresponding author: B. A. Gloy; e-mail: BG49@cornell.edu. particularly important because they tend to lock the farm into a particular production or marketing environment. Among the important strategic decisions facing the dairy farm manager is how to house animals and harvest forage production. In particular, the manager might choose to utilize a confinement housing system and use mechanical equipment to harvest forage or choose to implement the practice of rotational grazing, in which cattle spend much of their time outside and harvest forages as they are rotated through a series of pastures. Such a decision is very important because implementing a particular housing/harvesting strategy is not easily reversed. The construction of a free-stall confinement barn creates substantial "lost capital" that may not be recovered if the business is sold. On the other hand, profitable rotational grazing would likely involve a reduction in the machinery inventory and operating cost structure of the farm. As a result, such strategic decisions may impact profitability for many years.

Rotational grazing is an alternative to confinement housing and feeding of dairy cattle. Grazing may have several potential advantages, including improved herd health, reduced capital requirements, reduced time spent with crop farming, and potential lifestyle benefits to the farm manager. In a 1995 study of New York grazing farms, $43 \%$ of the farms identified labor and feed cost reduction as the primary reason for adopting rotational grazing (Nichols, 1996). While 11\% of the same farms indicated that improving herd health was the primary reason for adopting rotational grazing, only $6 \%$ of the farms identified increasing net farm income as the primary reason for adopting rotational grazing. Similarly, Hanson et al. (1998) found that none of the respondents in a 1992 study of 52 Pennsylvania grazing farms identified increasing profitability as the reason for adopting a grazing system. Such results indicate that profitability does not appear to be the most important factor in the decision to adopt a grazing system. It is possible that farmers view grazing as less or, at best, equally profitable to mechanical forage harvesting.

Previous studies have found that farmers often cite reasons other than profitability for adopting rotational 
grazing. This would suggest that farmers perceive nonfinancial benefits to grazing. However, the profitability of grazing is an important component of the grazing decision for several reasons. First, if grazing is less profitable than mechanical forage harvesting, producers who choose to graze must evaluate the trade-off of nonfinancial benefits with the financial cost of grazing. Second, if grazing is more profitable than mechanical forage harvesting, farmers should view this as an additional benefit of implementing a grazing system. In both cases, it is important to have an accurate measure of the relative profitability of grazing compared with mechanical forage harvesting.

The relative profitability of grazing systems is called into question for various reasons. Because more farms utilize confinement housing systems and mechanical harvesting of forages, one might presume that on average, confinement housing with mechanical forage harvesting systems must be more profitable than grazing systems. Likewise, adopting a grazing system constrains expansion at one site considerably more than does a confinement system. Under a grazing system, expansion beyond reasonable stocking rates would require replication of an entire operation at another site. In contrast, a confinement system has the advantage of being able to add additional units well beyond those possible under even the most aggressive grazing systems, provided that manure management allows for movement of nutrients away from one concentrated area.

Studies examining the profitability of grazing and mechanical forage harvesting have produced mixed results regarding the relative profitability of grazing. White et al. (2002) performed a controlled experiment in which the performance of grazing and confinement feeding systems was examined over a 4 -yr period. This study used randomized cow assignment and considered several treatment effects. The study found that although grazing cows on average produced $11.1 \%$ less milk than cows fed in confinement facilities, the feed costs associated with producing milk were lower in the grazing system. This resulted in average returns over feed costs per cow that were similar for grazing and confinement feeding systems.

In contrast to the controlled experimental approach used by White et al. (2002), other studies of grazing have examined the financial performance of farms that implemented these systems. These studies have relied on various definitions of grazing and various profitability measures. Typically, they have used a regression approach to determine the effect of grazing on profitability. Hanson et al. (1998) considered the factors that influenced the intensity with which a sample of 50 Pennsylvania farmers used grazing practices. They found that farms using more intensive grazing practices tended to be younger and more likely to adopt technology changes. They also found that farmers who used grazing to produce more than $15 \%$ of forage production needs had greater returns per cow and net farm income than farms that received less than $15 \%$ of forage needs from grazing.

Dartt et al. (1999) conducted a study of 53 Michigan dairy farms that used either rotational grazing or conventional management. The profitability analysis of 1994 data indicated that farms using grazing to obtain $25 \%$ of annual whole herd forage needs were more profitable than conventional farms. The study used a per cow measure of economic profit defined by net farm income less a charge for equity capital and farm labor to compare the profitability of the systems.

Winsten et al. (2000) studied the profitability of confinement (no grazing), traditional grazing (less than $75 \%$ of daily forage needs from grazing), and management-intensive grazing (more than $75 \%$ of daily forage needs from grazing). Under these definitions of grazing, only $12 \%$ of Vermont farms and $4 \%$ of Pennsylvania farms were using management-intensive grazing systems. Analysis of 96 farms from Pennsylvania and Vermont showed that herd size, milk per cow, debt per cow, and veterinary costs squared were variables that significantly influenced net farm income. However, the type of forage harvesting system was not associated with profitability. Unfortunately, the analysis explained magnitude of net farm income, not relative profitability.

Studies of the profitability of grazing have used various measures of profitability, but in order to compare farm profitability, some measures are clearly more appropriate than others. For instance, net farm income is dramatically influenced by farm size, making comparison of different size farms problematic. Likewise, although net farm income per cow corrects for the scale of the operation, profitability differences can be confounded by differences in financing, unpaid labor, and management. Measures of economic profit adjusted for farm size such as those suggested by Dartt et al. (1999) are the most useful measures of profitability because they adjust net farm income for differences due to unpaid labor, management, and equity capital. The rate of return on assets (ROA) if adjusted for differences in unpaid labor and management is another useful measure of profitability. Instead of charging for equity capital, interest expense is added to net farm income, thereby converting net farm income into a return to all capital that when divided by average total assets can be usefully compared across farms.

Those studies of grazing profitability conducted at the farm level did not consider the possibility that self 
selection might bias the regression parameter estimate measuring the profitability of grazing. Unlike data from experiments conducted under more controlled conditions with random subject assignment, such as the study conducted by White et al. (2002), farm data reflect the decisions of individual farmers to engage in certain activities. It may be possible that farmers who decide to be graziers may be more or less profitable than other farms even if their choices had been to not graze their herds. This data limitation is well known in research literature that attempts to estimate the returns to education, where those who attended college may have capabilities that would have allowed them to have experienced higher incomes even without attending college. This literature has developed various methods to account for this potential estimation bias (Heckman et al., 2000). Foltz and Lang (2001) did recognize that the decision to adopt grazing is potentially impacted by profitability and controlled for the potential endogenous nature of the grazing decision by using an instrumental variable technique. Contrary to the findings of Hanson et al. (1998) and Dartt et al. (1999), Foltz and Lang (2001) found that 22 graziers among 124 Connecticut dairy farms generated less average profit per cow than did the nongrazing herds.

Grazing and confinement feeding represent dramatically different allocations of technology and capital. Animals substitute for forage harvesting equipment in a grazing system. In addition, the farm manager is able to spend more time working on dairy-specific production management and practices. As a result, the farmer can specialize in working with cattle and devote considerably less time to crop production activities. It is an empirical question whether the choice of a particular housing/harvesting system tends to improve or reduce farm profitability, and there have been few empirical studies comparing the relative levels of profitability achieved by managers adopting grazing and confinement feeding. The objective of this study was to perform an empirical comparison of the profitability of grazing and confinement housing/mechanical forage harvesting systems.

\section{MATERIALS AND METHODS}

\section{Data}

The data used in this study consist of financial reports and operational data from 294 New York dairy farms participating in Cornell's dairy farm business summary for the year 2000. Farms that indicated that they rotationally grazed their herd at least 3 mo of the year, changed paddocks at least every $3 \mathrm{~d}$, and used grazing to obtain more than $30 \%$ of the forage consumed during the growing season were classified as grazing farms.
This resulted in 57 farms being classified as grazing farms and 237 being classified as nongrazing farms. The group classified as nongrazing farms may not be total confinement farms. Undoubtedly, some of these nongrazing farms met some of their forage needs with grazing practices, but did so in a manner that was less intensive than the farms that were classified as grazing farms. Descriptive statistics for each of these groups are reported in Table 1 . The measure of financial performance used in this study is the rate of ROA. The measure of ROA used in this study is generally consistent with the recommendations of the Farm Financial Standards Council (1997), with the exception that the change in the value of raised livestock was calculated at market values.

As Dartt et al. (1999) point out, it is important to select a profitability measure that can be accurately compared across farms. Small farms may have more unpaid family labor than large farms and may have less debt. When calculating the rate of ROA, interest expense is added, and both unpaid labor expenses and management charges are subtracted from net farm income. Thus, ROA is a measure that is not biased by differences in farm size, differences in unpaid labor, management, or asset financing.

Grazing and nongrazing farms have many different characteristics. The data in Table 1 indicate that grazing farms tended to have fewer cows (94) than nongrazing farms (282). Likewise, the differences in the scale of grazing and nongrazing farms led to different labor practices. Grazing farms used substantially fewer months of hired labor than nongrazing farms. While machinery investment per cow was higher for grazing farms, machinery expenses were lower for graziers than nongraziers. As expected, the nongrazing farms had a greater rate of milk production per cow. Nongraziers' higher rate of milk production per cow was often achieved with the aid of production enhancing practices. Nearly twice as many nongrazier producers used rBST, and nearly twice as many nongraziers used a parlor milking system as opposed to a stall milking system.

\section{Statistical Methods}

The impact of grazing on the rate of return on assets was estimated with a regression equation. The grazing adoption decision was included in the set of explanatory variables as a dummy variable identifying grazing farms. However, because the decision to graze is not necessarily randomly distributed in the population of farmers, one cannot match the "treatment" effect of grazing with the "control" of not grazing. Any estimation method failing to acknowledge and model this non- 
Table 1. Selected characteristics of 237 nongrazing and 57 grazing New York dairy farms, 2000.

\begin{tabular}{|c|c|c|c|c|}
\hline \multirow[b]{2}{*}{ Characteristic } & \multicolumn{2}{|c|}{ Nongrazing farms } & \multicolumn{2}{|c|}{ Grazing farms ${ }^{1}$} \\
\hline & Mean & $\mathrm{SD}$ & Mean & $\mathrm{SD}$ \\
\hline Rate of return on assets (\%) & 1.23 & 5.76 & 0.00 & 6.24 \\
\hline Net farm income/cow & 251.66 & 370.59 & 363.25 & 430.62 \\
\hline Number of cows & 282.13 & 323.63 & 94.40 & 73.09 \\
\hline Rate of milk production per cow $(\mathrm{kg} / \mathrm{cow})$ & 9166 & 1777 & 7670 & 1580 \\
\hline Milk receipts $(\$ / 100 \mathrm{~kg})$ & 29.43 & 1.85 & 30.00 & 3.95 \\
\hline Hay dry matter (metric tonne/ha & 2.70 & 1.19 & 2.38 & 1.06 \\
\hline Real estate investment ( $\$ /$ cow) & 3106.31 & 1576.73 & 3355.39 & 1740.54 \\
\hline Machinery investment (\$/cow) & 1473.23 & 703.06 & 1527.47 & 981.63 \\
\hline Machinery expense $(\$ /$ cow $)$ & 538.94 & 171.78 & 518.27 & 235.01 \\
\hline Operator age (yr) & 49.36 & 11.00 & 46.47 & 8.11 \\
\hline Operator education (yr) & 13.50 & 1.96 & 13.72 & 1.69 \\
\hline Percent using rBST & 0.62 & 0.49 & 0.30 & 0.46 \\
\hline Percent using a stall milking system & 0.31 & 0.46 & 0.67 & 0.48 \\
\hline Percent equity & 61.10 & 22.25 & 65.21 & 21.42 \\
\hline Hired labor $(\mathrm{mo})^{2}$ & 63.54 & 81.76 & 13.87 & 17.53 \\
\hline Hired labor per cow $(\mathrm{mo} / \mathrm{cow})^{2}$ & 0.16 & 0.08 & 0.11 & 0.08 \\
\hline
\end{tabular}

${ }^{1}$ Grazing farms were defined as farms that received $30 \%$ of their annual forage needs from grazing.

${ }^{2}$ Calculated only for 194 non-grazing and 39 grazing farms that hired labor in 2001.

random selection may bias estimates of the grazing treatment effect. The statistical issue is that the error term of the regression equation may be correlated with the treatment variable. This makes it necessary to employ a procedure that either eliminates this correlation or measures and includes the correlation in the regression. Instrumental variable techniques are often used to eliminate the correlation. This entails finding a new variable or set of variables that is highly correlated with the treatment variable but not correlated with the error term, and using these instruments as substitutes for the treatment variable. A slightly different approach, credited to Heckman (1979), is to explicitly model the selection process governing the grazing decision and use the information obtained to estimate the correlation between the error term of the regression equation and the treatment variable, in this case the practice of grazing. That is the procedure used here.

First, a probit adoption function was estimated to model the self selection of the grazing decision. The estimates of the probability of grazing adoption were then used to correct the error term in the ROA regression equation and eliminate the correlation between the grazing variable and the error term. The adoption and profitability regression equations can be estimated in a two-step manner, but the parameters are more efficiently estimated under joint maximum likelihood estimation, and thus joint estimation was used.

The first step is to estimate grazing adoption with a probit function with the specification:

$$
\mathrm{A}^{*}=\alpha \mathrm{Z}+\mu
$$

where

$$
\begin{aligned}
\mathrm{A}=1 & \text { if } \mathrm{A}^{*}>0, \\
\mathrm{~A}=0 & \text { if } \mathrm{A}^{*} \leq 0, \\
& \mu \sim \mathrm{N}(0,1) .
\end{aligned}
$$

$\mathrm{A}^{*}$ is an underlying index reflecting the likelihood of choosing grazing such that when $\mathrm{A}^{*}$ exceeds the threshold value (here 0 ) we observe the farmer grazing and $\mathrm{A}=1$. Matrix $\mathrm{Z}$ consists of exogenous variables that explain adoption, $\alpha$ is a vector of estimated parameters, and $\mu$ is an error term with mean zero and variance $\sigma^{2}$.

ROA is estimated by the following regression equation:

$$
y=\beta^{\prime} x+\left(\rho \sigma \sigma_{u}\right)\left\{\phi\left(a^{\prime} Z\right) / \Phi\left(a^{\prime} Z\right)\right\}+\varepsilon
$$

where $y$ is ROA. The vector $\mathrm{x}$ represents explanatory variables, including an indicator variable representing grazing farm, and $\beta^{\prime}$ represents the corresponding estimated parameter vector. The remaining terms represent the error structure correcting for self-selection bias because grazing farms may have greater (or lower) ROA even without grazing. The term $\varepsilon$ represents a standard normally distributed error with mean of zero. The terms $\phi$ and $\Phi$ are the probability density and cumulative distribution function of the standard normal distribution, respectively. The ratio of $\phi$ and $\Phi$ evaluated at $\alpha^{\prime} Z$ is the inverse Mills ratio, which reflects the truncation of a normal distribution at $a^{\prime} Z$ (Greene, 1997).

The multiplicative terms $\left(\rho \sigma \sigma_{u}\right)$ represent the covariance of the adoption equation [1] and grazing impact equation [2]. These covariances can be broken down into the standard deviations of the appropriate equations $\left(\sigma_{u}, \sigma\right)$ and the correlation $\rho$. However, given the 
structure of the model and the nature of the derived data, $\sigma_{u}$ cannot be estimated, so it is normalized to 1.0 (Greene, 1997).

Estimation of equations [1] and [2] is done using the software LIMDEP (Greene, 1998). The probit function [1] is first estimated by maximum likelihood using starting values estimated with ordinary least squares (OLS). The predicted values from the probit function are then used to calculate the inverse Mill's ratio, which is subsequently included as an explanatory variable when estimating equation [2] by OLS. Given the linear structure of these equations, a single parameter is estimated for $\rho \sigma$. Finally, equations [1] and [2] are estimated jointly by maximum likelihood using previous estimates of $\beta$ and $a$ as starting values. Given the structure of the maximum likelihood equation, separate estimates for $\rho$ and $\sigma$ are possible.

To accurately measure the impact of grazing on profitability, one must remove any correlation between the explanatory variable for grazing with the error of the profitability equation. This was accomplished by adjusting the error term of the profit equation with the inverse Mills ratio. The inverse Mills ratio is a transformation of the predicted value of the probability that a farm chose to graze and was estimated with a probit adoption function. The explanatory variables in the probit equation used to explain the probability that a farm chose to graze must be exogenous to the grazing decision. The variables used to explain the decision to graze were education, age, herd size measured by the natural logarithm of the number of cows, the type of milking system used by the farm, and regional location. The variables are difficult to adjust in the very short run and are likely to be exogenous to the grazing decision at least in the short-run time frame that is considered in this study.

\section{RESULTS AND DISCUSSION}

The parameter estimates for the probit adoption function estimated by maximum likelihood estimation are shown in Table 2. Of the factors considered, herd size appears to be the most important factor influencing adoption. As expected, farms with smaller herds are more apt to graze. Neither age nor education appears to influence the decision to graze. Even though many more grazing farms use stall-milking systems, when considered with the other factors, it does not serve to discriminate between grazing and nongrazing farms. As expected, given the harsher climate of the region, farms in Northern New York were less likely to graze. Of the 57 farms actually grazing, 17, or $30 \%$, were predicted graziers. This is a poor prediction, but reflects the situation that characteristics collected by the farm business summary are not particularly good measures of whether a farm will elect to graze. The inclusion of other measures such as the quality of the land owned by the farm, lifestyle attitudes, and farm goals would likely increase the predictive power of the probit equation. However, those variables are quite costly to collect and difficult to measure.

Table 3 shows the impact of the explanatory variables on ROA when controlling for possible sample selection bias. The determining variables are herd size, regional location, milk price, and milk production per cow. Not surprisingly, farms with larger herds, farms with high rates of milk production per cow, and farms that receive a higher price for their milk generated a greater ROA. Because the impact of herd size is modeled as the natural logarithm of the number of cows, its marginal effect on ROA is dependent on the initial level of cows. For instance, on a 100-cow dairy farm, a one-cow increase in herd size would add $0.01555 \%$, or roughly 1.5 basis points to ROA. It is somewhat surprising that, other things equal, farms in the Northern New York region have the greatest ROA. Dairy farms in that region tended to have the lowest cost of production. In addition, there are few alternatives to dairy production in that area and less competition for farmland, thereby leading to lower capital values and costs.

Although profitability is one of many different goals motivating farmers, the purpose of the study is to determine whether farms are forced to sacrifice profitability when grazing in order to fulfill nonfinancial goals. In a regression framework, an accurate assessment of the impact of grazing depends on no correlation between the error of the profit equation and the grazing variable. Because our data are empirical observations and not data from controlled experiment with treatments assigned at random, it seemed possible that treatment selection bias might exist. In other words, it was possible that even without the treatment of grazing, farms that have chosen to graze are more or less profitable than nongrazing farms.

Based on the maximum likelihood estimates of the ROA model that controlled for potential treatment selection bias, it is not possible to conclude that the impact of grazing on the rate of return is different from zero at any reasonable level of statistical significance. The results from the maximum likelihood estimation of the ROA sample selection model show that the parameter estimating the correlation between the errors of the likelihood of grazing adoption and ROA, rho, is not statistically different from zero. This indicates that farms that are inherently more or less profitable are not necessarily more likely to adopt the practice of grazing. In other words, there is no evidence of correlation 
Table 2. Maximum likelihood estimates of probit grazing adoption equation, 237 nongrazing and 57 grazing New York dairy farms, 2000.1,2

\begin{tabular}{lclc}
\hline Explanatory variable & Estimate & Standard error & z-Statistic \\
\hline Constant & 1.34 & 1.50 & 0.89 \\
Education beyond high school & 0.12 & 0.21 & 0.55 \\
Age (yr) & -0.02 & 0.01 & -1.29 \\
Natural log of number of cows & $-0.46 \dagger$ & 0.24 & -1.93 \\
Stall milking system (as opposed to parlor) & 0.23 & 0.29 & 0.80 \\
Sole proprietor & $0.39 \dagger$ & 0.23 & 1.68 \\
Northern New York region $^{3}$ & -0.13 & 0.42 & -0.32 \\
Central New York region $^{3}$ & $0.66 \dagger$ & 0.38 & 1.73 \\
Northern Hudson region $^{3}$ & -0.34 & 0.46 & -0.73 \\
Southeastern New York $^{3}$ & 0.17 & 0.43 & 0.39 \\
Western and Central Plateau region $^{3}$ & $0.94^{* *}$ & 0.34 & 2.77 \\
\hline
\end{tabular}

${ }^{1}$ Grazing farms were defined as farms that received $30 \%$ of their annual forage needs from grazing.

${ }^{2}$ Maximum likelihood estimates of probit equation jointly estimated with return on asset equation. Estimated with sample selection procedure in LIMDEP.

${ }^{3}$ Included as an indicator variable for the region with the Western and Central Plain region omitted from the model.

$$
\begin{aligned}
& \dagger P \leq 0.10 . \\
& * P \leq 0.05 . \\
& * * P \leq 0.01 .
\end{aligned}
$$

between the error of the profitability equation and the decision to graze.

Because sample selection bias does not appear to be a problem in this setting, it is possible to infer the effect of grazing from ordinary least squares estimation of the ROA equation. However, it is important to note that the general lack of fit in the probit equation influences this decision. It is possible that we are simply failing to explain the grazing adoption with the exogenous variables available in the dataset.

\begin{tabular}{|c|c|c|c|}
\hline Explanatory variable & Estimate & $\begin{array}{l}\text { Standard } \\
\text { error }\end{array}$ & z-Statistic \\
\hline Constant & $-31.67 * *$ & 5.20 & -6.09 \\
\hline Grazing farm & 1.46 & 1.18 & 1.24 \\
\hline Education beyond high school & -0.35 & 0.63 & -0.55 \\
\hline Age & 0.005 & 0.03 & 0.16 \\
\hline Natural log of number of cows & $1.56 * *$ & 0.54 & 2.86 \\
\hline Stall milking system (as opposed to parlor) & -0.56 & 0.87 & -0.64 \\
\hline Sole proprietor & 0.034 & 0.77 & 0.04 \\
\hline Northern New York region ${ }^{4}$ & $2.91 *$ & 1.14 & 2.55 \\
\hline Central New York region ${ }^{4}$ & 1.11 & 1.25 & 0.89 \\
\hline Northern Hudson region ${ }^{4}$ & 0.86 & 1.16 & 0.75 \\
\hline South East New York ${ }^{4}$ & 2.12 & 1.41 & 1.50 \\
\hline West Central Plateau region ${ }^{4}$ & 0.28 & 0.97 & 0.29 \\
\hline Milk receipts (\$'s per 100 kg) & $1.98^{* *}$ & 0.50 & 3.98 \\
\hline Milk production per cow (kg) & $2.66 \mathrm{E}-4^{* *}$ & $4.67 \mathrm{E}-5$ & 5.68 \\
\hline Sigma $^{5}$ & $4.95^{* *}$ & 0.20 & 25.25 \\
\hline $\mathrm{Rho}^{6}$ & 0.15 & 0.21 & 0.69 \\
\hline
\end{tabular}

Table 3. Maximum likelihood estimates of return on asset (ROA) model, 237 nongrazing and 57 grazing New York dairy farms, 2000..$^{1,2,3}$

${ }^{1}$ The dependent variable, ROA, was measured as a percent.

${ }^{2}$ Grazing farms were defined as farms that received $30 \%$ of their annual forage needs from grazing.

${ }^{3}$ Maximum likelihood estimates of probit equation jointly estimated with ROA equation. Estimated with sample selection procedure in LIMDEP.

${ }^{4}$ Included as an indicator variable for the region with the Western and Central Plain region omitted from the model.

${ }^{5}$ The variance of the error of the adoption function.

${ }^{6}$ The correlation between the error of the ROA equation and the probability that a farm grazes.

$\dagger P \leq 0.10$.

$* P \leq 0.05$.

$* * P \leq 0.01$. 
Table 4. Ordinary least squares estimates of return on asset (ROA) equation, 237 nongrazing and 57 grazing New York dairy farms, 2000..$^{1,2,3}$

\begin{tabular}{|c|c|c|c|}
\hline Explanatory variable & Estimate & $\begin{array}{l}\text { Standard } \\
\text { error }\end{array}$ & $t$-Statistic \\
\hline Constant & $-30.72 * *$ & 5.20 & -5.90 \\
\hline Grazing farm & $1.92 *$ & 0.87 & 2.21 \\
\hline Education beyond high school & -0.34 & 0.61 & -0.56 \\
\hline Age & 0.005 & 0.03 & 0.16 \\
\hline Natural log of number of cows & $1.51 * *$ & 0.53 & 2.82 \\
\hline Stall milking system (as opposed to parlor) & -0.52 & 0.88 & -0.59 \\
\hline Sole proprietor & 0.054 & 0.68 & 0.08 \\
\hline Northern New York region ${ }^{3}$ & $2.91 * *$ & 1.01 & 2.88 \\
\hline Central New York region ${ }^{3}$ & 1.22 & 1.17 & 1.04 \\
\hline Northern Hudson region ${ }^{3}$ & 0.84 & 1.04 & 0.81 \\
\hline Southeast New York ${ }^{3}$ & $2.14 \dagger$ & 1.26 & 1.69 \\
\hline West Central Plateau region ${ }^{3}$ & 0.33 & 0.98 & 0.34 \\
\hline Milk receipts (\$’s per 100 kg) & $1.92 * *$ & 0.67 & 2.85 \\
\hline Milk production per cow (kg) & $2.62 \mathrm{E}-4^{* *}$ & $4.09 \mathrm{E}-5$ & 6.41 \\
\hline$R$-Square & 0.289 & & \\
\hline$F$-Statistic & $8.75^{* *}$ & & \\
\hline \\
\hline \multicolumn{4}{|c|}{${ }^{2}$ Grazing farms were defined as farms that received $30 \%$ of their annual forage needs from grazing. } \\
\hline \multirow{2}{*}{\multicolumn{4}{|c|}{$\begin{array}{l}{ }^{3} \text { Included as an indicator variable for the region with the Western and Central Plain region omitted from } \\
\text { the model. }\end{array}$}} \\
\hline & & & \\
\hline \multicolumn{4}{|l|}{$\dagger P \leq 0.10$} \\
\hline \multicolumn{4}{|l|}{$* P \leq 0.05$} \\
\hline
\end{tabular}

The decision to use the OLS estimates to determine the impact of grazing on profitability is supported by the results of the treatment selection model. Specifically, this is suggested by the lack of statistical significance of the parameter rho, which measures the correlation between the decision to graze and profitability. One cannot reject the hypothesis that this parameter is equal to zero at a meaningful confidence level. Thus, it is not possible to reject the hypothesis that there is no correlation between the error of the profitability equation and the decision to graze. This result can be the case for at least two reasons. First, no correlation may exist. Second, due to a lack of explanatory power, our probit results may not be an accurate estimate of the decision to graze.

Table 4 shows the results obtained when the ROA equation is estimated with OLS. One should note that the parameter estimates are very similar to those found in Table 3. The OLS results indicate that other things equal, grazing farms generate a ROA that is $1.9 \%$ greater than nongrazing farms. In the sample selection model, the estimate was of similar magnitude, but not statistically different from zero. The statistical significance in the OLS model and insignificance in the sample selection model is not unexpected as the standard errors in the OLS model are substantially smaller, reflecting the lack of predictive error introduced by the probit adoption estimation. The results would seem to provide modest evidence that grazing farms are generating a greater average ROA than nongrazing farms.

\section{CONCLUSIONS}

The paper uses year 2000 data and an econometric methodology to determine the impact of rotational grazing for New York dairy farms that have chosen to participate in the farm business summary program. While these farms are not necessarily representative of the entire dairy industry or other dairy regions, they provide evidence regarding the profitability of grazing and mechanical forage harvesting systems. It should also be noted that the data reflect profitability from one year, and the decision to rotationally graze or use mechanical forage harvesting has long-term impacts that can influence factors such as a farm's ability to expand.

A simple comparison of the average rate of ROA shows that the ROA for grazing farms is numerically lower than the average ROA for nongrazing farms. This would lead to the conclusion that grazing is not as profitable. However, the results of this paper using regression analysis suggest that the return from grazing is at least as great as the return from nongrazing. The regression analysis controls for several factors that influence profitability, and considers the possibility that the "treatment" effect of grazing may be biased by selfselection. Empirically, self-selection does not appear to 
be a problem. Results suggest that much of the difference between the average ROA for grazing and nongrazing farms can be attributed to factors such as location, rates of milk production, milk receipts, and herd size.

This provides some evidence that farms may be able to use rotational grazing as an alternative to mechanical forage harvesting and generate at least as high if not higher rates of return on assets than nongrazing farms. Because farmers often cite nonfinancial reasons for adopting grazing systems, one might expect that they would have to pay an income penalty for adopting grazing and receiving such benefits. The results suggest that this is not the case when one compares grazing farms and nongrazing farms, holding other things equal.

For those farms seeking nonfinancial benefits from rotational grazing, the results are important because they indicate that these farms are not necessarily forced to pay an income penalty for adopting a grazing system. These farmers can obtain other frequently mentioned benefits of grazing, such as lifestyle improvement and the opportunity to spend more time working with cattle and less time working with crops. At the same time, they can maintain the level of profitability that they would be likely to generate with a mechanical forage harvesting system.

\section{ACKNOWLEDGMENTS}

The authors thank Linda Putnam for her assistance with data processing and preparation. The authors would also like to thank the anonymous reviewers and the section editor for helpful comments and suggestions.

\section{REFERENCES}

Dartt, B. A., J. W. Lloyd, B. R. Radke, J. R. Black, and J. B. Kaneene. 1999. A comparison of profitability and economic efficiencies between management-intensive grazing and conventionally managed dairies in Michigan. J. Dairy Sci. 83:2412-2420.

Foltz, J., and G. Lang. 2001. The adoption and impact of management intensive rotational grazing (MIRG) on Connecticut dairy farms. Selected paper, Northeastern Agricultural and Resource Economics Association, Bar Harbor, ME.

Farm Financial Standards Council. 1997. Financial Guidelines for Agricultural Producers. Farm Financial Standards Council, Naperville, IL.

Greene, W. H. 1997. Econometric Analysis, 3rd ed. Prentice Hall, Upper Saddle River, NJ.

Greene, W. H. 1998. LIMDEP Version 7 User's Manual, Revised Edition. Econometric Software, Inc., Plainview, NY.

Hanson, G. D., L. C. Cunningham, M. J. Morehart, and R. L. Parsons. 1998. Profitability of moderate intensive grazing of diary cows in the Northeast. J. Dairy Sci. 81:821-829.

Heckman, J. 1979. Sample selection bias as a specification error. Econometrica 47:153-161.

Heckman, J., J. L. Tobias, and E. Vytlacil. 2000. Simple estimators for treatment parameters in a latent variable framework with an application to estimating the returns to schooling. National Bureau of Economic Research. Working paper 7950.

Nichols, M. E. 1996. An Economic Analysis of Rotational Grazing in New York State. M. S. thesis, Cornell University, Ithaca, NY.

White, S. L., G. A. Benson, S. P. Washburn, and J. T. Green, Jr. 2002. Milk production and economic measures in confinement or pasture systems using seasonally calved Holstein and Jersey cows. J. Dairy Sci. 85:95-104.

Winsten, J. R., R. L. Parsons, and G. D. Hanson. 2000. A profitability analysis of dairy feeding systems in the Northeast. Agric. Res. Econ. Rev. 29(October):220-228. 